\title{
Agro-Urban Landscape: the case study of Monteruscello
}

\author{
Alessandra Como, Luisa Smeragliuolo Perrotta, Carlo Vece \\ DICIV-Dipartimento di Ingegneria Civile. University of Salerno. Salerno, Italy. \\ E-mail: acomo@unisa.it, lsmeragliuoloperrotta@unisa.it, carlovece@gmail.com
}

\begin{abstract}
Studies on morphology and on the urban form should not be detached from social aspects and from the responsibility of architects and policy makers. The issue becomes even more complicated in the case of cities with a high number of buildings under public ownership or urban areas of great dimensions. In Italy there is a very rare case of recent urban foundation that is the neighbourhood of Monteruscello in the city of Pozzuoli, in South Italy. Built in the 1980s to face the problem of bradyseism events that had made uninhabitable the historic city areas, Monteruscello today, for its dimension, can be considered a "city in the city" with the 90\% of the buildings under public ownership. The neighbourhood's project was designed by Agostino Renna who developed it through analogical composition with fragments referred to other places and cities. The architect applied an urban model based on morphological studies, adapting it to the specific geography of the site. Till now the neighbourhood has never acquired its own identity becoming one of the most degraded areas of the city. This paper deals with the issue of urban form and morphology starting from the study of Monteruscello from the initial design project and the related critical issues through a new experimental design project of an agro-urban landscape that involves fifty hectares of public green spaces - now abandoned - turning them into agricultural land for urban use and growth resource.
\end{abstract}

Keywords: Urban Renewal, Morphology, Process, Landscape, Agriculture.

\section{Introduction}

This paper presents an urban proposal for the borough of Monteruscello, at the periphery of the city of Pozzuoli, in South Italy, describing it together with theoretical investigation on the issues of morphology, urban process and landscape, all tightly related to the case-study. The proposal aims to convert the open un-used areas of the borough into urban agriculture land and to trigger from here a process of urban transformation investing economic, social and physical aspects.

Pozzuoli is a city in the Campania Region, and more specifically within the volcanic area called Phlegraean Fields. In March of 1986, under the emergency of bradyseism, about
20,000 people were moved from the ancient city of Pozzuoli to the new neighbourhood of Monteruscello, built beyond the hills around the gulf. The new urban landscape was not able to become - and still is not - a place of reference for the life of the residents, lacking of spaces of uses and meanings, besides being architecturally designed and carefully studied from an urban point of view. The families who had the opportunity, once the emergency had ended, returned to live in other areas of the city, and today only the most disadvantaged part of the population lives in Monteruscello. Problematic social conditions are combined with a difficult urban environment, in particular for the character of emptiness, anonymity, and decay of the common spaces. While Pozzuoli 
is a city strongly related to its history and heritage, with relevant archaeological remains, Monteruscello has to deal with the problems connected to the public housing and new urban interventions.

The proposal here presented aims to solve some of the problems within the neighbourhood through a design strategy that invests the open areas of the neighbourhood. The project is winner of the UIA-Urban Urban Innovative Actions funding program promoted by the European Union. It addresses urban issues left open.

The borough layout project was developed in reference to Italian theoretical studies on the city and on the morphological form. The neighbourhood had been designed in detail in every part and also the study of the green spaces had a significant role. Monteruscello's realisation was eventually realised of separate parts and the green spaces were left as indefinite areas. Today, the neighbourhood has 50 hectares of unused green spaces of various size, and most of them are interstitial to the residential areas.

The presented proposal shifts the point of view from the form of the city to the enlarged territory observed in its complexity and within a variety of issues. While the morphological studies of Italian school interested the built parts of the city, we now aim to look at the city through the open green spaces. This paper relates, through a theoretical and design oriented reflection, with the spheres of morphology and landscape with the aim of reasoning on a link between the two themes through a design project that rather than working on the built, introduces a process of transformation and urban growth for the neighbourhood centred on its landscape dimension.

\section{Urban model within the reality}

Confronted with the emergence of the bradyseism that struck Pozzuoli in 1983, political decision-makers faced the problem with a definitive solution by quickly building a new neighbourhood to accommodate the people and respond to a possible strengthening of the phenomenon. The chosen site was an agricultural land with widespread rural construction, located in a peripheral condition with respect to the city of Pozzuoli but still central to the Phlegraean Fields. The University of Naples was in charge of the project with the architect Agostino Renna responsible for the design project. The great dimension of the intervention together with the task of designing many public buildings made Monteruscello an exceptional project opportunity. Now days, it is one of the most recent example of public housing district in Italy built from the scratch and due to its dimension it could be defined as a public city. The design is based on a morphological study of an autonomous urban centre with public and residential buildings that come together and with a hierarchy of pedestrian passages, streets and large roads that connect it with the other parts of the city of Pozzuoli.

Agostino Renna design project starts with a reflection on the urbanization of the Phlegraean Fields characterized by parts that are built over time and which create an urban progression that grows moving from the sea toward the countryside. Monteruscello is conceived as part of this system as a new urban cluster between the countryside and the urbanized border. "The reference model - Renna writes - for the entire urban structure can be that of a linear city, built in parts, where at its extremities there are the historic centre of Pozzuoli and the new settlement; this can become [...] the centre of reference for the extensive urbanized countryside» (Renna, 1984). After having defined the urban role of the new Monteruscello, Renna designs the overall project of the district from the idea of using «a simple and regular geometry, in which the repetition of the an urban module leads to a logical order that controls the numerous parts and the elements» (Renna, 1984). The measures and the elements dimension of the new neighbourhood form are derived from the study of the characters of the historic city and its architectural heritage. Renna draws on a repertoire of ideas which he reuses manipulating and adapting them to the specific site. 


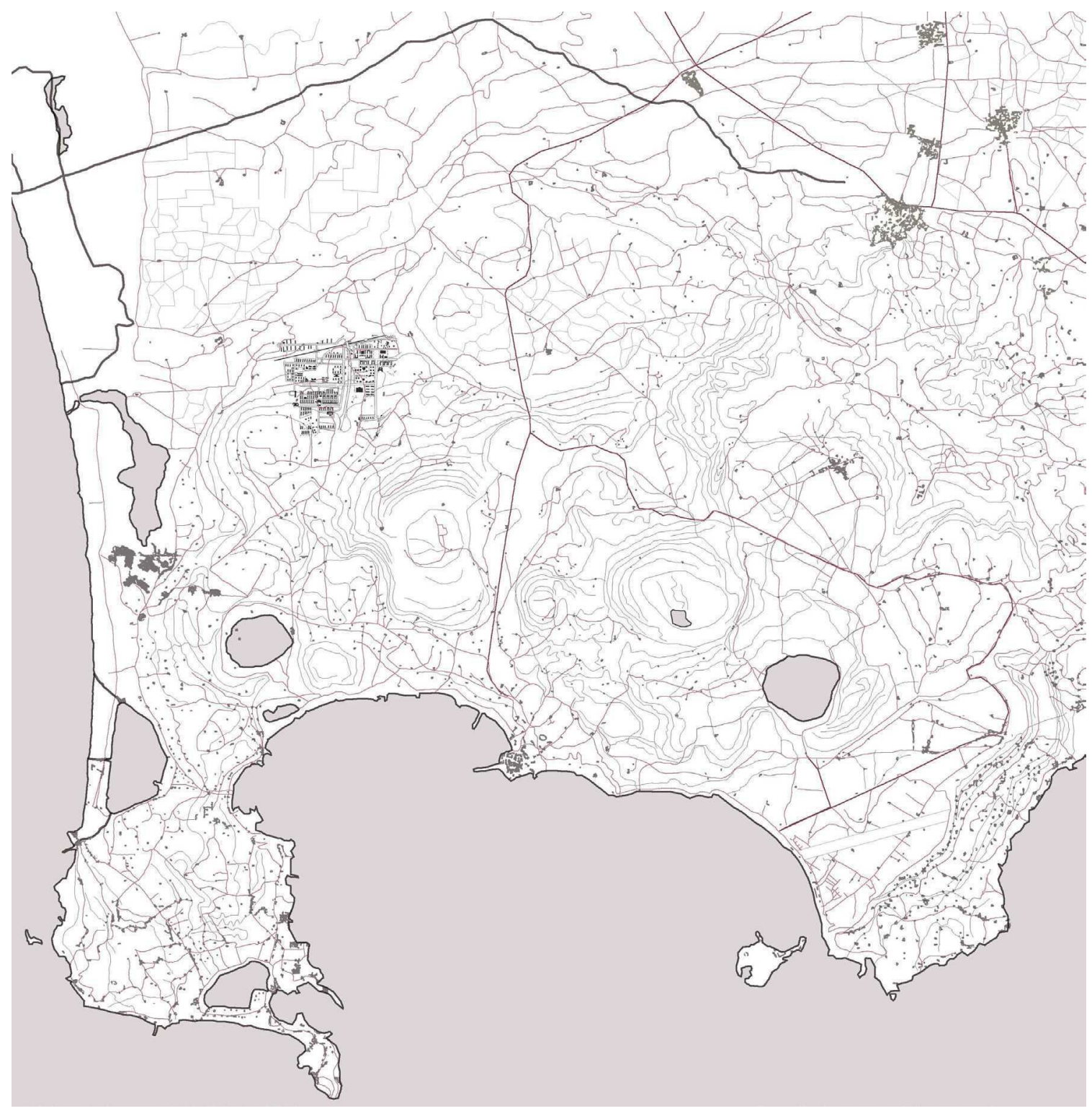

Figure 1.

The neighbourhood is conceived in separate parts, from both a morphological point of view and for realisation timeframe. In this process, the partitioning - like mosaic tiles - is a gimmick used to simulate the city's history and its growth over time. The overall design and the set of parts are held together by «an absolutely rigid physical reference system, a modular network based on harmonic relationships. This network stretches invisible threads on the territory so that every house, road, and tree can find, at any time and independently, its defined place» (Renna, 1984). The design project is based on different dimensions that correspond to the scale of the neighbourhood, to the autonomous small town cluster, and

to the territorial scale, all recognizable at the morphological, architectural and functional levels.

The neighbourhood is subdivided into three main parts. The first, at the highest level and visible from afar, corresponds to the core of the borough with the main public buildings. The second part, at a lower level, is composed of an archaeological park at the centre, surrounded by residential areas with predominantly single-family houses. The last part houses the railway station, retail and offices. In all the three areas there are housing buildings of different types and with different formal and dimensional hierarchies. Also the variety of 


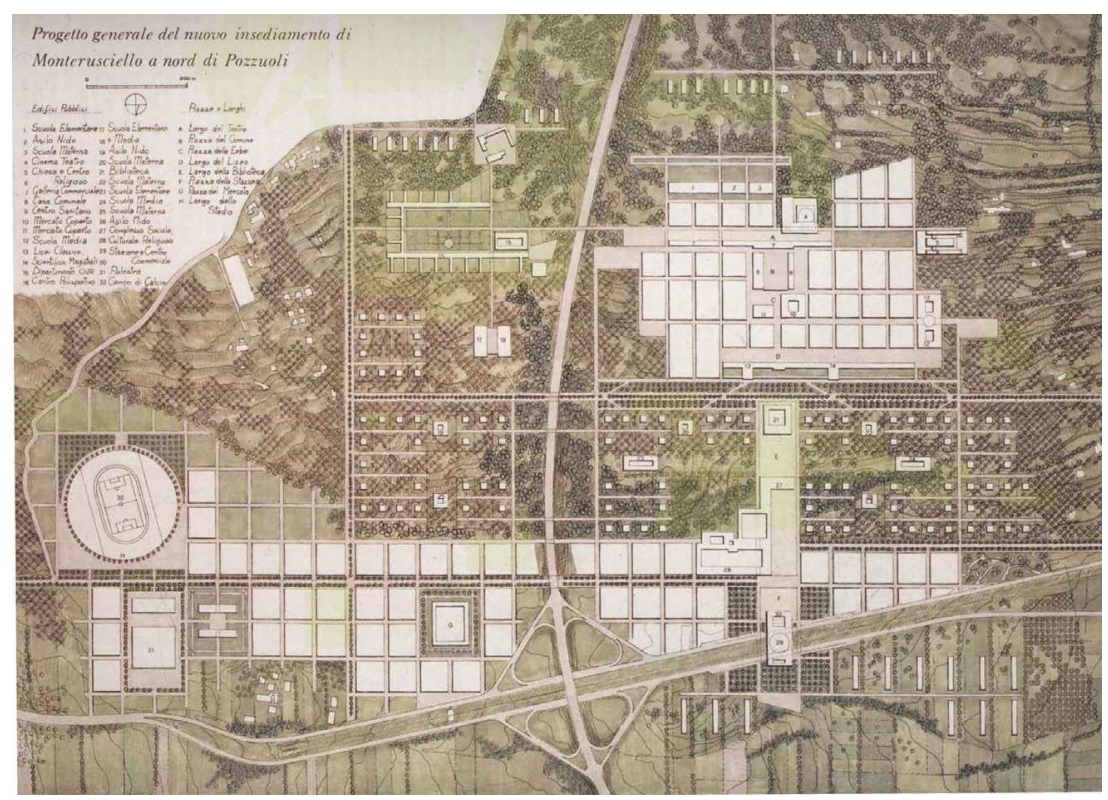

Figure 2.

the street dimension responds to hierarchicaldimensional criterion underlying the design. In the upper part of the city, the urban fabric repeats the structure of a traditional historic city made of small blocks, squares and public buildings that "play an "evocative" role on the historic city. In a city built in a single time and with repetitive building techniques, - Renna writes - the public building can express its individuality in the sense of the normality, the already seen, that is the familiar». (Renna, 1984). While the public buildings need a design project that would reinforces the relationship with the urban core, the housing buildings have to have on the contrary a different character. «Here the form is not so important, it is the typology the essential issue. A courtyard can be beautiful only because of orange trees; a road can take advantage of a row of mimosas from which it takes its name or for the pergolas of wisteria rather that for the particular design of the houses; it matters more the lively atmosphere of a square or the silent shade of a garden than the refined design of a prospect» (Renna, 1984).

The design project of the vegetation and the tree system were considered important landscape features since the beginning. The elements of nature are entrusted with the dual role of preserving the character of the pre-existing countryside and of marking the collective public spaces. "Recovering the features of the countryside within which the buildings are immersed, marking the great paths and collective places with pine trees, giving character to a road through the use of precious trees, making a garden cosy and familiar with fruit trees» are some of the peculiarities indicated for the green spaces. In relation to the transformative power that would have been derived from the correct definition of the green spaces, «the relative poverty of the housing becomes secondary, and it is possible to overcome the rush and lack of good building technique» (Renna, 1984).

The neighbourhood realisation has never been completed. Housed and abandoned early by those who had the chance to return to the city centre, Monteruscello combines problems of architectural deficiencies and social issues. The highest degradation is seen in the unrealized structures from the original project, resulting in authentic urban voids, forming with their loss, interruption of the use of the urban space and consequent abandonment even of the nearby areas. A further level of degradation is represented by the realized but still un-used buildings, which are today in a state of neglect. The reason of Monteruscello's failure is perhaps to be found in the incompleteness of its realization and in the bad quality of the prefabrication used 
for the building construction, while meantime there are also underlying morphological issues still open to question. Though the design project took into account the morphology of the site, the abstract and modular forms did not easily adapt to the complex actual topography. The design project was concentrated on its urban form; the actual condition opens up a question: is the definition of an architecture form sufficient to realise the urban environment

\section{Designing a process: architecture as part of a set of actions}

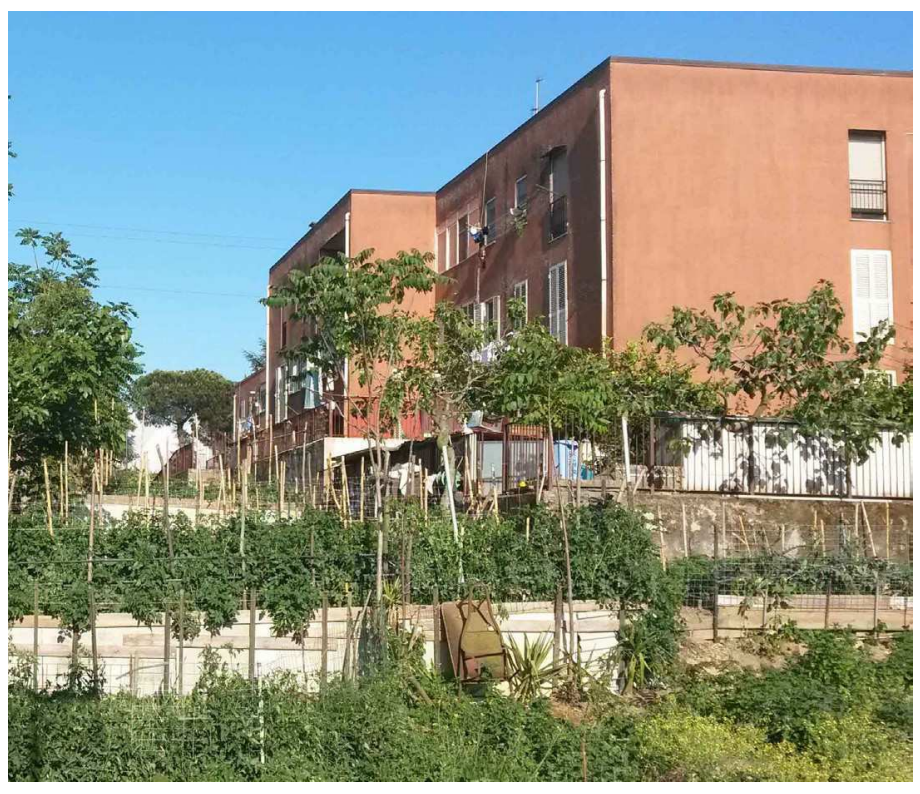

Figure 3.
Now days to face the topic of Monteruscello regeneration, rather than looking at the urban form, it is necessary to involve areas and spaces left in the rift between the city's design and its construction. Among these, the nearly 50 hectares of unused open areas become an opportunity for a regeneration of the neighbourhood in relation to landscape and production. A strategy of transformation was therefore studied for the open areas of Monteruscello. Rather than a fixed design project, the proposal is a set of actions, which enables and triggers a process of transformation.

The processual approach is here seen as the right response to the contemporary condition. The design project becomes a complex set of different levels and topics, able to adapt itself to new scenarios for the same place from time to time. The multi-temporality of the project is one of the central issues: in fact, urban transformations have elastic dynamics and varying reaction times. The design experiences of James Corner Field Operation or Michel Desvigne and Christine Dalnoky, for example, prove that it is necessary a phased approach, a multi-time and multi-scale process. A clear example is the Freshkills Park Landfill Competition in 2001, designed by James Corner Field Operations and Stan Allen. Concerning this, Alexander Wall comments it with reference to the general view of the Landscape Urbanism, a cultural approach to urban planning and architectural design emerged as a theory at the end of the 1990s: «Many Landscape Urbanism projects, like Fresh Kills Park by Field Operations have a 30 year phasing plan. This is because of the time that remediation of brownfield sites takes and also the funding (economic conditions) that is available. Issues of change are also important as Landscape Urbanism projects are responsive and must anticipate change as well as responding to it». (Wall, 2004).

The processual approach does not only involve time issues, it also affect the design project on a conceptual level, changing it from static to dynamic. Desvigne and Dalnoky write concerning with their project Lyon Confluence in 2001: "The slow method - four-year of studies - is to explore the territory according to certain themes, to identify the mechanisms at work and to imagine their mastery theme by theme or stratum by stratum. The objective is to conceive, not a project but a series of projects. We do not envisage a hypothetical and illusory definitive state, but a succession of states corresponding to different stages of metamorphosis. The exterior surfaces are born, disappear, move according to the evolution of the buildings and the rhythm of the releases of land. They constitute a kind of moving mapping in the image of the rotation of agricultural crops. While the order suggested the composition of 
a 30-hectare unit park, we propose a "system of parks", diffuse and mobile, which invest immediately in a temporary or perennial way, any available external surface ». (Dalnoky and Desvigne, 2001).

Along these lines, our proposal rather than a traditional architectural design project, has the form of a planned process involving a variety of disciplines within a set of connected actions at different scales and velocities. The process has the main goal of urban poverty reduction in the neighbourhood, where poverty is understood both in social and economic sense and within the physical environment. The project concept is built upon the presence of vast public property areas - seen as a resource - and their use for urban agriculture; other actions are anchored to it involving economic, social and urban issues.

Urban agriculture - implemented through bio-intensive and organic techniques - is used as the trigger of the process of transformation: a chain of interconnected urban policies will generate effects on the social economy, on the production and on the physical environment. Agriculture has been connected to a production and marketing circuit where the natural materials from cultivation processes will be transformed to be used for ecological construction and placed on the market. Both the agriculture and the production circuit will be managed through an educational programme, which will prepare young and jobless people to the organic agriculture and production practices. The creation of a Cooperative at the end of the educational cycles will ensure the continuity of the cultivation, that is the sustainability of he project itself. An additional educational track will prepare to the innovative business opportunities connected to the agriculture. The proposal also envisages connections with the local market in order to tighten the network of food production. The involvement of schools and institutions, together with local associations will occur through specific events. Finally, the architectural intervention will make use of abandoned public buildings, refurbished to provide the necessary facilities to run the agriculture and production practices, and will define spaces for events, pedestrian and cycle paths within the agriculture areas in order to allow the integration and use of agriculture within the urban environment.

All the actions of the process are connected within a system that envisages cross-relations and mutual interactions. The architectural design project is one of the actions, loosing that central role that had before within the morphological approach which characterised the original Renna design plan.

\section{A new urban role for the agriculture}

Central to the proposal is the implementation of agriculture within the open un-used areas of the borough. Now days there is a new interest in agriculture and it has become a common practice to include cultivated areas within the cities such as communal gardens and allotments, educational farms and even rooftop farms. In reality, city farming is not a new idea; the Incas settlement of Machu Pichu, Peru, to cite a famous example, included a residential area together with a terraced one, dedicated to intensive crop. What is though changing now days is the role and meaning assigned to agriculture. Rather than opposite to the city, it started to be seen as included in it or we could also say that it is the city itself which is considered in a broader view which allows a variety of environments to be comprised within its meaning - cultivated land as well as areas occupied by large structures and infrastructures. As a consequence the traditional dichotomy city/countryside is overcome and new creative relationships can occur with the presence of agriculture within the urban realm. The impact can affect not only the physical environment but it also involves the social and the economic levels, in particularly ecological balance, sustainability, and food production. Moreover, agriculture becomes part of the city's landscape: while before it was seen just from a production's perspective, today it has gained a landscape interest.

Several theoretical investigations on the subject - such as the work by Pierre Donadieu - and design project experimentations reinforce this topic, starting from the Desvigne and 


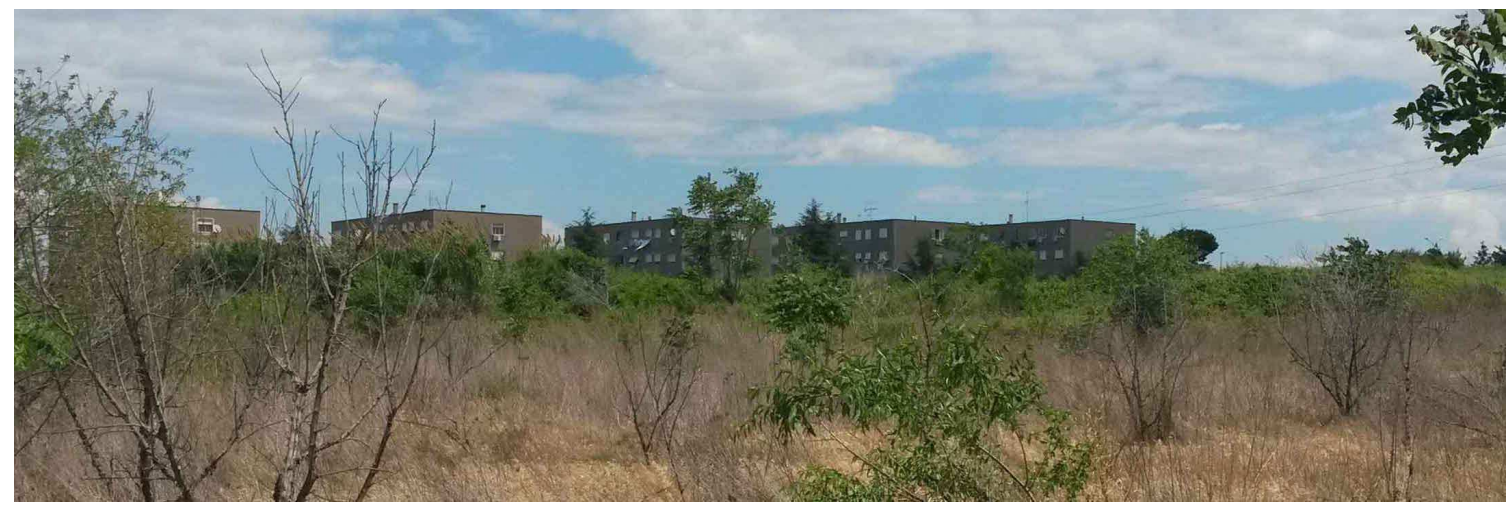

Figure 4.

Dalnoky landscape design projects of the 1990s such as the Parc de la Lironde in Montpellier or the urban park of Théols at Issoudum, where the space is considered neither part of the city nor of the countryside, but an urban living environment within nature.

Along these lines, our proposal for the Monteruscello neibourhood, investigate opportunities between the built and the agricultural areas for the definition of a new agro-urban landscape. Prior to its construction Monteruscello was a predominantly agricultural area; historical sources refer to the agrarian nature of the area already at the time of the colonies of Pozzuoli and the nearby Cuma. The proposal project aims to implement agriculture within the permaculture approach, which is oriented to the recovery of traditional crops, meeting the agricultural vocation of the area. Moreover the envisaged bio-intensive techniques will generate a dense vegetation, which will act as an urban garden that will change during the year, according with the seasons and the cycle of crops.

\section{New interpretative paradigma: from architecture to landscape for a search of new relationships}

The architectural design project studied within our proposal aims to define those spaces that allow the integration and use of agriculture within the city; outdoor areas designed for pedestrian paths, event space, covered areas, seating, skate parks and cycle path, all studied along portions of farmland so that architecture and cultivated areas can together become a new landscape for leisure, recreation and educational activities.

The architectural project has been set within an enlarged view which departs from the mere formal approach. It starts from a re-reading of Renna site plan in order to understand its reasons and goals. This has been then observed within the actual reality that revealed that some of the choices resulted abstract while other had been absorbed by the common use. This was the case for example of some staircase and pedestrian paths to which we decided to connect with. The project studies a new system of paths and crossings between the cultivated areas and the built areas. Here a significant feature is the presence of archaeological traces within the abandoned green areas. An archaeological park had been envisaged by the Renna site plan but was never realized. The urban fabric, modular and geometric, has no relation with the archaeological findings and it has also disclosed the possibility of exploring the continuity of some of these traces. Fragments of Roman walls and cisterns reappear among the expanses of green areas, now abandoned. Some old rural buildings also appear in the open areas, without any relationship with the street structure. All these existent traces tell us of a different territory in respect to the current city with directions that almost cut across the geometric urban layout of Monteruscello. The project proposes to retrieve 


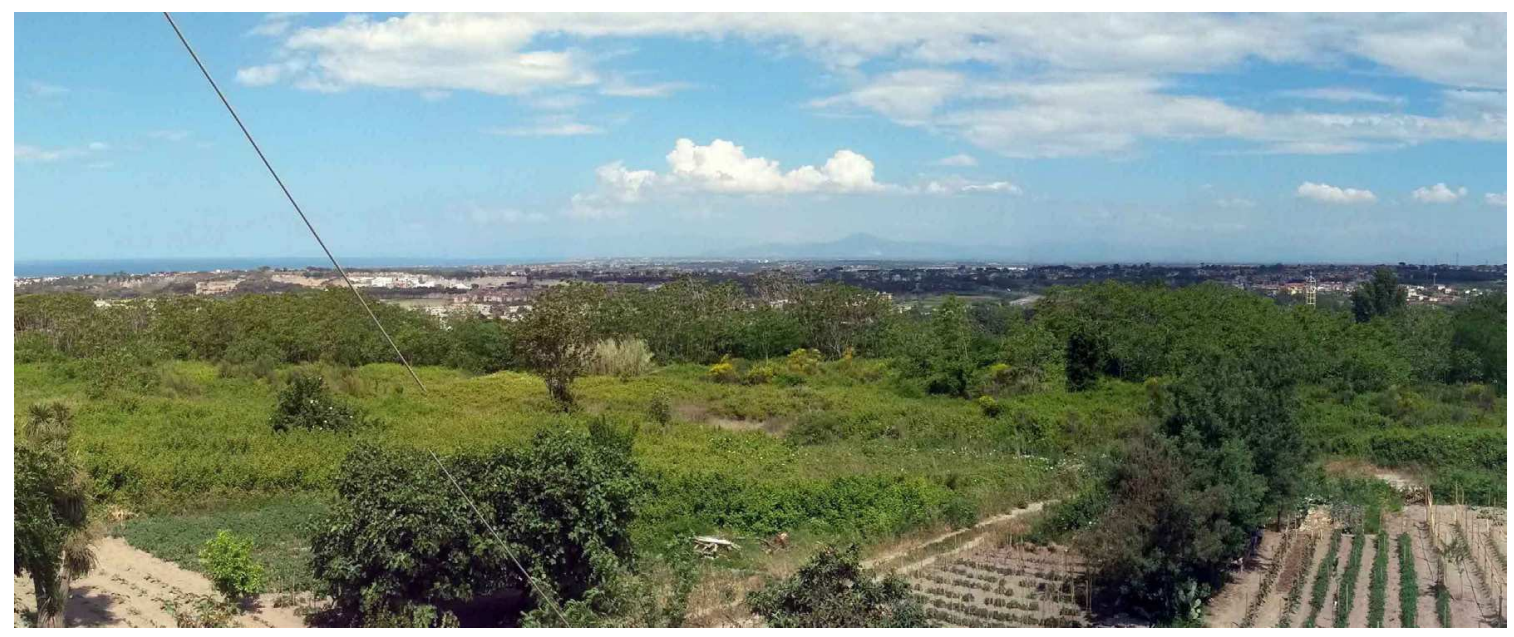

Figure 5.

the city's ancient trails in order to realise new pathways that enable pedestrian cuts through the abstract road grid. All the new elements paths, benches, coverings and so on - follow those old traces directions instead of those of the grid. They also point toward specific views, in order to re-orient oneself. While the neighbourhood is autonomous from all the preexistent geographical references, our project is defined through a new set of relationships which are found outside the actual quarter layout, toward new visual horizons that include the ancient part of the city and the coast, the archaeological site of the Greek Cuma, as well as a quarry and other reference points within the landscape. The goal is to create territorial references.

Also the cultivation is design planned, together with the agricultural experts, in order to reinforce the main territorial directions and the planned view points, and to recreate difference of levels through terraces and high grounds, that is to design a topography that the tabula rasa of the new neighbourhood had erased.

Our project therefore shifts the point of view towards the landscape and from here through nature, topography and the geographic repositioning through selected views - it intends to rethink the urban spaces of the neighbourhood, together with the paths, the natural and the morphological characters. The construction of the agro-urban landscape thus becomes the construction of a new image of the city, of a different way of living its spaces and crossing it, opening towards a strongly landscape dimension.

\section{Conclusion}

Today Monteruscello still divides the scholars; some are still anchored to the ideas which generated the neighbourhood foundation project - a defence which takes the form of taking sides of the Italian morphological school -, others consider it an example of urban design and theory failure, being its problematic state a proof of their invalidation.

We believe it is still possible to work within the reality without having to necessarily define ideological positions. Along these lines, the first step of the work has been the understanding of Monteruscello design project, that is the investigation of the morphological aspect. From here issues of form were overcome by a processual approach, which allowed the integration of social aspects and new relational purposes which linked the architectural solution to the landscape.

The proposal here presented reverses the traditional point of view in dealing with urban issues referred to the city form. The project starts from the study and the use of abandoned green areas and retrieves morphological issues concerning the built areas through a critical reflection on the use and the role of a new agrourban landscape within the neighbourhood. Morphological issues underlying the city's design are addressed to a wider discourse 
where the urban study rather than the resolution from the top of problems of urban form, aims to consider a variety of aspects and takes into account the territorial dimension of the neighbourhood, seen in its actual geography.

\section{References}

Renna, A. (ed.) (1980) L'illusione e $i$ cristalli: immagini di architettura per una terra di provincia (Clear, Roma).

Renna, A. (1984) "Il progetto di Monteruscello", in Siola, U. (ed.) Progetto Pozzuoli : rapporto di sintesi sul lavoro svolto al 30 giugno 1985 (La Buona Stampa, Ercolano) 96-101.

Escalona, F. and Francese D. (eds.) (1987) Monteruscello: l'impianto urbano e gli edifici pubblici (F. Giannini, Napoli).

Romano, M. (1986) "Agostino Renna: Monteruscello (Pozzuoli)", Domus 674, 25-33.

Venezia, F. (1987) "Interventi per il progetto Pozzuoli”, in Ferlenga, A. and de Bevilacqua, C. (eds.) Le città immaginate. Un viaggio in Italia. Nove progetti per nove città (Electa, Milano) 210-213.

Bruni, F., Renna, P. and Santangelo, M. R. (eds.) (1993) La città di fondazione : Il quartiere di Monteruscello : $5^{\circ}$ seminario internazionale di progettazione, 1993 (Edizioni Scientifiche Italiane, Napoli).

Giglia, A. (1997) Crisi e ricostruzione di uno spazio urbano: dopo il bradisismo a Pozzuoli : una ricerca antropologica su Monteruscello (Guerini, Milano).

Pagano, L. (ed.) (2012) Agostino Renna: rimontaggio di un pensiero sulla conoscenza dell'architettura : antologia di scritti e progetti 1964-1988 (Clean, Napoli).

Capozzi, R. (ed.) (2016) Agostino Renna: la forma della città (Clean, Napoli). 